\section{Biobanks and consent with a terminal clause}

To the Editor: We have read with great interest the article "A Systematic Literature Review of Individuals' Perspectives on Broad Consent and Data Sharing in the United States," by Garrison et al. ${ }^{1}$

We believe that the emergence of biobanks requires an introduction of appropriate legal and ethical norms for their functioning. One of the basic and primary requirements for the storage and usage of the genetic material is donor's consent. The issue of consent has already been broadly debated and is analyzed in Garrison and colleagues' article; however, we would like to stress a matter that seems to be underestimated and even unnoticed in terms of consent: time restrictions. Time restrictions, to a great extent, organize and clarify the already existing legal principles and may ultimately prove crucial in the functioning of biobanks as one of the factors affecting willingness to give consent for genetic research.

Various models of consent function in the legislature (e.g., implied, proxy, authorized, dynamic), but none, including the basic broad consent for biobank research, indicates time limitations. ${ }^{2}$

We believe that consent (independent of the type) should always include a time aspect-in this case, information on how long the genetic material will be stored and what will happen to the material after the established time passes. Lack of such a provision in the consent form is equivalent to providing incomplete information. Additionally, because it is difficult to predict what will be allowed and possible in the distant future, donors are uncertain of possible future applications and benefits (e.g., being entitled to property rights in case of commercial use of the genetic material). The absence of precise solutions regarding the terminal application of stored genetic material may lead to the disrespect of the donors' subjectivity, misinterpretation of the rules governing storage of the genetic material, and possible claims statements.

Failure to determine the storage time causes the donor to lack information about the following:

1. How the material may be used in the distant future

2. Whether he or she will have access to the genetic material and for how long and to what extend

3. What will happen with the stored material after his or her death
4. Whether anyone will have the right to inherit the rights to the genetic material and, in case of commercial use, monetary remuneration

We propose the introduction of a broad written form of informed consent with a terminal clause that assumes determining time restrictions on genetic material storage and usage.

As a certain solution (model), we propose the concept of perpetual usufruct, which in Polish Civil law lasts for 99 years. ${ }^{3}$ In case of genetic material storage, the time period should also be specified in years; however, it should be much shorter, e.g., 10-15 years. After this time, the donor could once again be asked for consent, which may vary from the original one depending on the then-existing medico-legal situation.

This provision will ensure a sense of ownership of the genetic material and the respect of the donor's subjectivity. It will also create an ideal stability in the donor-biobank relationship with possible determined guarantees throughout this period.

From a legal perspective, the formula of a broad informed consent to donate, store, and use the genetic material should obligatorily include a provision on time restrictions, it should contain precise information on who (and to what extent) could inherit the rights to the genetic material and, in case of commercial use, to the possible remuneration after the donor's death. It should also contain information on what is going to happen to the genetic material after the stated time period has passed and there is no additional consent for its further usage. We believe that providing all of this information would facilitate the decision-making process.

\section{DISCLOSURE}

The authors declare no conflict of interest.

\section{Rafał Kamil Patryn, JD ${ }^{1,2}$ and Anna Zagaja, $M A^{1}$}

${ }^{1}$ Department of Ethics and Human Philosophy, Medical University of Lublin, Lublin, Poland; ${ }^{2}$ Provincial Committee for Adjudication on Medical Events, Lublin, Poland. Correspondence: Anna Zagaja (anna.zagaja@o2.pl)

\section{REFERENCES}

1. Garrison NA, Sathe NA, Antommaria AH, et al. A systematic literature review of individuals' perspectives on broad consent and data sharing in the United States. Genet Med; e-pub ahead of print 11 November 20156.

2. Pawlikowski J, Sak J, Marczewski K. The ethical and legal problems connected with the activity of biobanks. Diametros 2009; 19:106-118.

3. Act of 23 April 1964 - Civil Code (Journal of Laws 2014, item 121).

Advance online publication 31 March 2016. doi:10.1038/gim.2016.26 